\title{
Impact of the Adoption and Safe Families Act on youth and their families: Perspectives of foster care providers, youth with emotional disorders, service providers, and judges
}

\author{
Kristen R. Humphrey,*, Ann P. Turnbull ${ }^{\mathrm{b}}$, \\ H. Rutherford Turnbull $\mathrm{III}^{\mathrm{b}}$
}

${ }^{a}$ Humphrey Education Services, 507 N. Mesquite St., Olathe, KS 66061, United States

${ }^{\mathrm{b}}$ Beach Center on Disability, University of Kansas, United States

Received 20 October 2004; received in revised form 28 January 2005; accepted 21 February 2005

Available online 31 May 2005

\begin{abstract}
This article, which describes a component of a larger research project, focuses on participants' perspectives on (a) ways that the Adoption and Safe Families Act (ASFA) affected access to services for children with emotional or behavioral disabilities and their families, and (b) other ways that the ASFA affected children with emotional or behavioral disabilities and their families. Fifty-eight interviews with 33 participants (youth in out-of-home placements, their parents, foster care providers, service providers, and judges) took place. Participants reported that they believed the ASFA shortened the amount of time families had for correcting problems while their children were in custody. Some service providers may feel less inclined to help families because the law seems to require less from service providers than was required in the past. In addition, participants believed that when courts make decisions involving families, those decisions are more likely to call for termination of parental rights than for reunification. The investigators offer recommendations regarding these issues that involve the ASFA, families, and children with disabilities.
\end{abstract}

(C) 2005 Elsevier Ltd. All rights reserved.

Keywords: Adoption and Safe Families Act; Families; Children; Foster care; Disability

* Tel.: +1 9133970989.

E-mail address: krrohu@comcast.net (K.R. Humphrey). 


\section{Introduction}

The United States Congress passed the Adoption and Safe Families Act (ASFA) in 1997 (P.L. 105-89, 111 Stat. 2115, 1997). ASFA revised and clarified the Adoption Assistance and Child Welfare Act (P.L. 96-272) of 1980. When Congress enacted the ASFA, legislators intended to rectify at least two problems in the foster care system (H.R. Rept. No. 105-77, 1997). One problem was foster drift, the prolonged period between a child's removal from his or her biological family and placement into permanent care (reunification with the child's family or adoptive placement). The other problem was an apparent disregard for children's welfare by social service agencies that allegedly returned children to their biological parents too quickly, putting them at risk once again for maltreatment.

The ASFA potentially affects a large number of children nationwide. Nationally, the ASFA significantly affects over 530,000 children in out-of-home placements (Administration for Children and Families, 2003). In Kansas, the ASFA affects more than 6000 children in out-of-home placements (Children's Defense Fund, 2004).

\subsection{Timelines}

Congress addressed foster drift in the ASFA by mandating that a permanency planning hearing be held within 12 months of a child entering foster care (42 U.S.C. Sect. $675(5)(C), 2000)$, rather than the 18 months that the previous law required. A permanency plan must be developed at this hearing to address whether a child will return to his or her family of origin, and if so, when this will take place.

The ASFA added time-limited family reunification services as a category of family preservation and support (42 U.S.C. Sect. 629a(a)(7)(A), 2000). These services may be provided to a child who is removed from the home and to his or her parents to help facilitate safe, timely reunification. Reunification services are limited to 15 months, beginning on the date the child enters out-of-home placement. Services may include (a) individual, group, and family counseling; (b) substance abuse treatment; (c) services targeted at domestic violence; (d) mental health services; (e) temporary child care and therapeutic services for the family; and (f) transportation to and from any of these services (42 U.S.C. Sect. 629a(a)(7)(B), 2000).

If the permanency plan does not include reunification with the family of origin, the permanency plan must state whether the child will be referred for adoption or legal guardianship. If the plan is for adoption, the state must file a petition for termination of parental rights. The ASFA requires states to consider terminating parental rights more quickly than the former child welfare laws did. Under the ASFA, states must file for TPR when a child has been in foster care for 15 of the most recent 22 months, or if the child is an abandoned infant; or, the states must justify why it is inappropriate to do so (42 U.S.C. Sect. 675(5)(E), 2000). States are required to initiate TPR when a court determines that the parent has committed murder, voluntary manslaughter, or serious acts of violence against the child as previously described (42 U.S.C. Sect. 671(a)(15)(D), 2000). 


\subsection{Reasonable efforts}

Since the 1980s, when the Adoption Assistance and Child Welfare Act (AACWA) was enacted, states have been required to make reasonable efforts to prevent out-ofhome placements and to reunify families after out-of-home placement occurs (42 U.S.C. Sect. 671, 2000). While holding hearings on the AACWA, Congress was persuaded that too many children were being returned to their biological parents and then subjected to maltreatment (H.R. Rept. No. 105-77, 1997). Because of this, legislators clarified the term reasonable efforts. The ASFA states that the "child's health and safety shall be the paramount concern" (42 U.S.C. Sect. 671(a)(15)(A), 2000). The ASFA clarified the meaning of reasonable efforts and emphasized safety by explaining when reasonable efforts should not be made because of risks to the child's health and safety (42 U.S.C. Sect. 671(a)(15)(B)(D), 2000).

Reasonable efforts to prevent out-of-home placement or to reunify families are not required if a court has determined that (a) the parent has subjected the child to aggravated circumstances as defined by state law (such as abandonment, torture, chronic abuse, or sexual abuse); (b) the parent has committed murder or voluntary manslaughter of another child of the parent; (c) the parent has aided or abetted, attempted, conspired, or solicited to commit such murder or voluntary manslaughter; (d) the parent has committed felony assault resulting in serious bodily harm to any of the parent's children; or (e) the parent's rights have been terminated involuntarily in the case of one of the child's siblings (42 U.S.C. Sect. 671(a)(15)(D), 2000). In addition, states have the option of identifying "aggravated circumstances" under which reasonable efforts are not required. For example, Kansas defines "aggravated circumstances" as abandonment, torture, chronic abuse, sexual abuse, or chronic, life-threatening neglect of a child (Kansas Code for Care of Children, 1999).

When a state agency is not required to make reasonable efforts to prevent outof-home placement or reunify a family, the agency must make reasonable efforts to place the child in another permanent placement. When a state petitions for TPR, it is also required to recruit, identify, approve, and process a qualified adoptive family unless (a) at the state's option, the child is being cared for by a relative, (b) a state agency has documented a compelling reason that filing for TPR would not be in the child's best interest, or (c) the state has not provided adequate family preservation or reunification services in instances where these services would have been appropriate as part of the requirement for reasonable efforts (42 U.S.C. Sect. 675(5)(E), 2000). Reasonable efforts to reunify a family may be made at the same time as reasonable efforts to place a child for adoption or with a legal guardian.

\subsection{Implementation of ASFA in a statewide-privatized system}

This research took place within the context of the Adoption and Safe Families Act of 1997 (ASFA) and privatization of foster care services in Kansas. Kansas implements the law through a wholly privatized system (James Bell Associates, 1999). At nearly the same time that the ASFA was passed, Kansas privatized all child 
welfare services except child protective services. The privatized system began in 1996, and was completely phased in by March 1997.

This article, which describes a component of a larger research project (Humphrey, 2002; Humphrey, Turnbull, \& Turnbull, in press), focuses on perspectives of judges, service providers, foster care providers, foster care youth, and their families of origin regarding the following research questions: (a) In what way(s) do youth and their families, foster care providers, service providers, and judges perceive that the ASFA has helped/ hindered children and families' access to services?; and (b) In what other ways do youth and their families, foster care providers, service providers, and judges perceive that the ASFA has affected children and families?

\section{Method}

Qualitative methods including individual interviews and court document reviews were the sources of data collection. In-depth interviews or case studies allow researchers to capture information that might be missed if participants are restricted to "forced-choice" answers (Banyard \& Miller, 1998). Qualitative methods are warranted when one explores "why" something happened, the unanticipated outcomes of a policy, and potential solutions to problems (Marshall \& Rossman, 1995). Qualitative methods are also useful when evaluating programs that develop or change as participants and conditions change (Woodhouse \& Livingood, 1991).

The lead researcher conducted semi-structured interviews (Honey, 1987), and sought information about youth in foster care placements who had emotional disabilities/disorders (ED). The state child welfare agency does not maintain quantitative data on this population, and the agency's databases (past and present) do not indicate which children have ED or other disabilities. Therefore, there was no simple way to identify this population for quantitative investigation. Further, quantitative methods would not allow for the depth of information desired.

A Participatory Action Research Committee (PAR) was created to give advice to the researchers on developing research protocol, implementing research, and dissemination to increase the probability that findings would help the intended research beneficiaries (Breda et al., 1997; Gatenby \& Humphries, 1996; Penuel \& Freeman, 1997; Turnbull, Friesen, \& Ramirez, 1998). The PAR method involves researchers and stakeholders as equal partners throughout the research process (Breda et al., 1997). The overall PAR goal is change resulting from the research (Gatenby \& Humphries, 1996). PAR honors and values the experience and knowledge of research participants, who often are from oppressed groups (Reason, 1998).

Stakeholders in the research, including young adults who had been in foster care, foster parents, adoptive parents, parents of youth in foster care, service providers, child welfare professionals, child welfare researchers, and judges, served on the committee. The committee communicated through a listserv, since one member was deaf and this was her communication preference. The amount of contact varied throughout the study, with the PAR committee consulted several times a week during some phases, and once every several weeks during other phases. Most PAR members were involved on a 
regular basis, and a few who had limited availability were consulted occasionally. The PAR committee was most helpful during development of interview guides, when they helped shape some of the questions.

\subsection{Participants}

When the study began, three private contractors provided foster care services for the state. Two sites within each of the three contract areas were selected. Half the sites were in rural areas and half were in urban areas. The sites were selected first, and then participant groups within these sites were selected. Five instrumental cases comprising a collective case study were ultimately involved in the research (Stake, 1998). Data from varied geographical regions were sought, and within those regions, families who would provide maximum variation of the sample were sought (Patton, 1990). The 33 participants were selected in two steps using purposive sampling.

Through the PAR Committee process, the researchers identified a "guide". Berg (1998) suggests that one way of obtaining entry and beginning initial relationships in qualitative analyses is to locate a guide, i.e., a person who is indigenous to the group being studied. This guide can facilitate connections with other potential participants and "vouch for" the researcher in a process sometimes called snowballing, which can help build up the sample (Berg, 1998).

A respected district court judge served as the guide for this study by assisting with selection of sites and identifying other potential judges. Then, Area Chiefs from the Kansas Department of Social and Rehabilitation Services (SRS) were contacted in those areas. The judges and SRS were essentially gatekeepers for the data (Berg, 1998). The Area Chiefs identified a social worker or social work supervisor who found families who fit the study criteria and would provide maximum sample variation (Patton, 1990). Because the researcher knew some families would choose not to participate, SRS contacts were asked to identify six families for each family desired. The agency was provided with information packets that explained the study and asked for participation, and the agency mailed the packets to the potential participants. To maintain confidentiality, SRS contacts identified potential participants while withholding identifying information from the researcher. Families who were willing to participate filled out brief informational sheets and mailed them to the researcher, who then contacted the families to determine if they met the study criteria. The family that best met the criteria was chosen in sites in which more than one family was willing to participate.

The researchers selected five families to participate in the study. One sibling pair participated, so there were six youth participants. The lead researcher sought one or two primary caregivers from the families each youth had lived with before entering out-ofhome placement. In two instances, this caregiver was one biological parent. In one family, the caregivers were two adoptive parents who had reared the youth since infancy. In two cases, caregivers were a biological parent and a stepparent. The youth and their families of origin were selected from five areas of the state. Two families (three youths) were from counties with populations of less than 41,000. Three families were from counties with populations greater than 170,000. Three families were European 
American, one was African American, and one was Hispanic. The Hispanic parent was a native Spanish speaker.

Table 1 highlights demographic characteristics on the youths, who ranged in age from 11 to 17 . Two of the youths were female, and four were male. Each youth had experienced challenging behavior and/or psychiatric diagnoses that included depression, oppositional defiant disorder, attention deficit disorder, adjustment disorder, and bipolar disorder. Five of the parents (of four of the youth) had histories of substance abuse. Domestic violence had been present in three families. In addition, one youth had mental retardation, and another had borderline intellectual functioning. Two of the parents had histories of depression. Poverty was a factor in three families' lives.

Each of the youth in the study entered foster care because of their behavior as related to their mental health. In all but one family, the parent or parents either requested help with the mental health and behavior concerns, and that led to out-of-home placement, or they specifically asked for the child to be removed from the home because they did not know what else to do. In each of these cases, there was a delay getting the child into an appropriate placement after the family made the request. In one of the cases, staff from a community mental health center assisted the family with the request for placement and advocated for the family throughout the process. Four of the families needed mental health services for either the child, the parent, or both, long before the crisis that led to the out-ofhome placement. By the time the child or family received mental health services, the challenges were so great that the services did not help enough to prevent the out-of-home placement. Likewise, three families were involved with family preservation services. Although these services provided some benefit, they were not enough to prevent later outof-home placement.

The child court judges were the authorities who presided over the child-in-need-of-care cases. Five of the judges had authority in the youth participants' cases. Two additional judges who were interviewed lived in areas where study families were sought, but no families meeting the criteria were identified. Each judge was European American. Three were female; four were male.

Service providers were identified by each youth or family as having been particularly helpful during the family's involvement with the child welfare system. The lead researcher sought effective service providers in order to understand what worked, and to focus on solutions. Two service providers worked for a family support agency, and two others worked at area mental health centers. One service provider worked for SRS, the state's child welfare agency. Another service provider was employed by a private foster care agency. During the study, this service provider accepted employment with the new contractor in her area when foster care contracts changed. Five of the service providers were European American; one was African American. All were women.

The lead researcher sought a foster care provider for each participant family. One youth had been in a residential setting during most of his out-of-home placement. In this case, the lead researcher asked his parents to identify someone from the residential setting who had the most experience with the youth and who had developed a relationship with the youth. Another youth had only been in residential settings when the study began, so the researcher asked the youth's parents to identify someone at the residential setting who was familiar with the aforementioned youth. This person was interviewed. While the study was 
Table 1

Characteristics of youths

\begin{tabular}{|c|c|c|c|c|c|c|}
\hline \multirow[t]{2}{*}{ Characteristics } & \multicolumn{6}{|l|}{ Youths } \\
\hline & A & B & $\mathrm{C}$ & $\mathrm{D}$ & $\mathrm{E}$ & $\mathrm{F}$ \\
\hline Location & Urban & Rural & Urban & Urban & Rural & Rural \\
\hline Race & African American & Hispanic & European American & European American & European American & European American \\
\hline Age & 17 & 17 & 15 & 15 & 15 & 11 \\
\hline Gender & Male & Female & Male & Female & Male & Male \\
\hline Type of disability* & $\begin{array}{l}\text { Mental retardation } \\
\text { with psychiatric } \\
\text { behavioral } \\
\text { impairment }\end{array}$ & $\begin{array}{l}\text { Borderline intellectual } \\
\text { functioning, depression }\end{array}$ & $\begin{array}{l}\text { ADHD, oppositional } \\
\text { defiant disorder }\end{array}$ & $\begin{array}{l}\text { Major depression, } \\
\text { oppositional defiant } \\
\text { disorder }\end{array}$ & $\begin{array}{l}\text { Adjustment disorder } \\
\text { with mixed emotional } \\
\text { features }\end{array}$ & $\begin{array}{l}\text { Bipolar disorder, } \\
\text { oppositional defiant } \\
\text { disorder }\end{array}$ \\
\hline IEP?** & Yes & Yes & Yes & No & Yes & Yes \\
\hline Legal status & $\mathrm{CINC}^{* * *}$ & CINC & $\mathrm{CINC} / \mathrm{JO} * * * *$ & CINC & CINC & $\mathrm{CINC} / \mathrm{JO}$ \\
\hline Permanency Plan & Independent living & Independent living & Reunification & Reunification & Reunification & Reunification \\
\hline $\begin{array}{l}\text { Length/type of } \\
\text { involvement } \\
\text { with SRS }\end{array}$ & $\begin{array}{l}\text { Family preservation } \\
\text { 1990; out-of-home } \\
\text { placement 1990- } \\
\text { 1993; out-of-home } \\
\text { placement } 1997 \\
\text { to present }\end{array}$ & $\begin{array}{l}\text { Informal supervision } \\
\text { 12/1994-10/1995; state } \\
\text { took custody } 10 / 95 ; \\
\text { out-of-home placement } \\
\text { 1996-present }\end{array}$ & $\begin{array}{l}\text { Family preservation in } \\
\text { 1994; out-of-home } \\
\text { placement 1997-present }\end{array}$ & $\begin{array}{l}\text { Known to SRS since } \\
1997 \text {; out-of-home } \\
\text { placement in } 1998 \\
\text { and } 2 / 2000 \text {-present }\end{array}$ & $\begin{array}{l}\text { Under SRS supervision } \\
\text { beginning } 8 / 1989 \text {; } \\
\text { out-of-home placement } \\
8 / 1993 \text { to } 2 / 1995,1996 \text {, } \\
\text { and } 6 / 1999 \text { to } 7 / 2000\end{array}$ & $\begin{array}{l}\text { Under SRS supervision } \\
\text { beginning } 8 / 1989 \text {; } \\
\text { out-of-home placement } \\
\text { in } 1991,1992 \text { to } 1995 \text {, } \\
\text { and } 9 / 1999 \text { to } 8 / 2000\end{array}$ \\
\hline Placements & 6 & 4 & 18 & 8 & 9 & 16 \\
\hline
\end{tabular}


taking place, the youth entered a foster care placement and the foster care provider was interviewed as well. Each foster care provider was European American; one was male.

\subsection{Data collection}

The lead researcher conducted 58 interviews with 33 participants over a period of 8 months. Participant interviews were the primary data source for this study. Court case files were also examined. An interview guide was used, but participants were also asked to raise issues they found important (Taylor \& Bogdan, 1998). Open-ended descriptive questions were used and allowed for flexibility in discussion (Kadushin, 1990; Taylor \& Bogdan, 1998). A separate interview guide was used for each stakeholder group. Interview guides were three to five pages long, similar in structure and questions, but adapted to each stakeholder group. Individual interviews with each member of the participant groups took place in the location of the participant's choice.

The youths in out-of-home placements, parents, and foster care providers were interviewed two to three times. The first interview asked participants to "tell their story" of their experience with out-of-home placement (Morse, 1994). Beginning an interview with "free recall" and following up with more direct questions is recommended for interviewing children (Docherty \& Sandelowski, 1999). In a study that used both free recall and specific and direct questions, Steward and Steward (1996) found that information from free recall was consistently more accurate than information gathered from specific or direct questions (as cited in Docherty \& Sandelowski, 1999).

After the participant told his or her story, the lead researcher switched to a semistructured interview (Honey, 1987). There was review of topics from the first interview and a reading of transcripts when possible. The review helped create a question guide for the second interview (Taylor \& Bogdan, 1998). After the second interview, the lead researcher used the same review process which was used to decide if a third interview was needed. A third interview was conducted with one of the youth's parents and with one of the youth's foster care providers. Each youth interview generally took about $1 \mathrm{~h}$; parent and foster care provider interviews ranged from 1 to $3 \mathrm{~h}$ each.

Service providers and judges were interviewed two to three times. Interviews addressed participant families' as well as service providers' and judges' general experiences with foster care. Interviews were semi-structured and held in locations participants chose. Subsequent interviews followed up on topics that were not fully covered in the first interviews. Two judges participated in third interviews. Service provider and judge interviews each lasted about $2 \mathrm{~h}$. Table 2 provides sample interview questions.

Information was collected from each youth's court case files and court social history files. The judge assigned to each youth's case provided these documents. The lead researcher used this information to learn more about each family's history with child welfare services (i.e., family services, family preservation, and foster care), to fill gaps in information, and to verify information that participants shared. The lead researcher also identified the youth's age at the time of first out-of-home placement; total amount of time in placement; number of out-of-home placements by type; cited reason for out-of-home placement; the youth's special education status, if applicable; the youth's psychiatric diagnosis, if applicable; court orders in place for the youth (e.g., visitation, therapy, 
Table 2

Sample interview questions

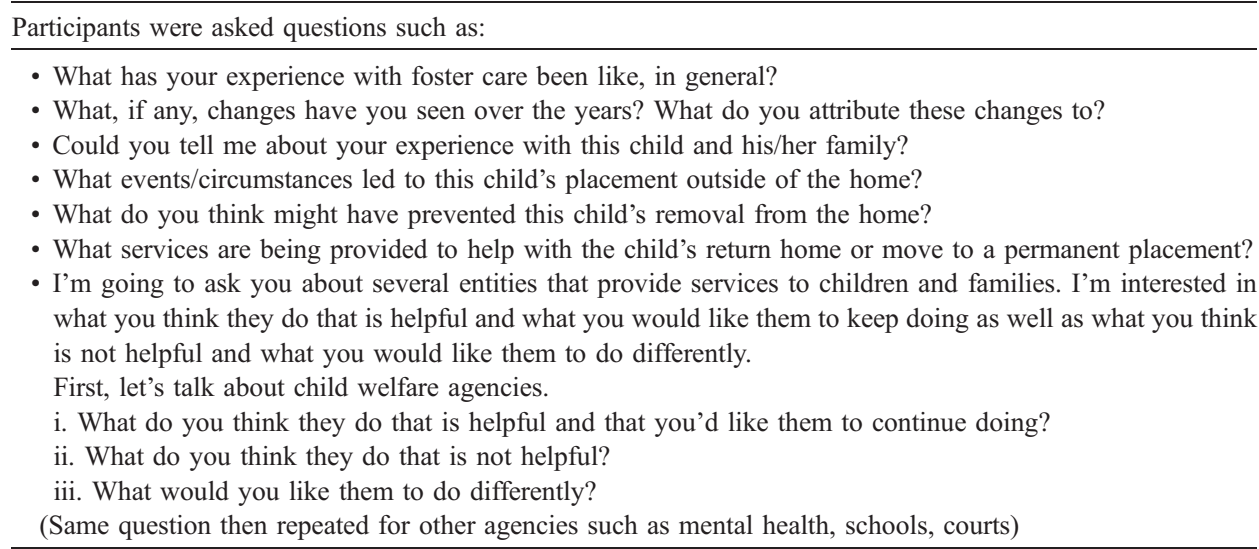

These questions are provided as samples. They are not all inclusive, probes were deleted for the sake of brevity, and the question guides were structured differently among participant groups.

psychological evaluation); court orders in place for the parent(s) (e.g., visitation, therapy, drug/alcohol evaluation, parenting classes); whether siblings were also in out-of-home placement; past and current permanency plans; and types of services the child should be receiving.

\subsection{Data analysis}

Data analysis addressed 58 interview transcripts and 5 files from court document reviews. The interviews were recorded and transcribed. Notes from the court document reviews were typed into a word processing file. Transcripts and document files were then filed in The Ethnograph, a code-and-retrieve computer software program (The Ethnograph, 1998). The lead researcher also created a chronology for each family that included the timeframe and circumstances of the family's initial involvement with the state agency, when the child(ren) entered state custody and out-of-home placement, what placement moves occurred, and what services were received before placement, during placement, and after reunification, when applicable. Analysis also involved creating matrices of categories, placing evidence in the categories, and creating data displays for examining data (Miles \& Huberman, 1994; Taylor \& Bogdan, 1998; Yin, 1994).

When analysis began, the researchers used inductive theory (Miles \& Huberman, 1994; Taylor \& Bogdan, 1998). The lead researcher and an assistant read the first 12 transcripts and assigned code words that described sections of the text independently. The next step was assigning codes to the transcripts without a predetermined list of code words. Some sections of text received only one code word, and others received more than one code word. The researchers discussed each coded block of text. When these blocks of text were coded differently, the researchers discussed it until reaching consensus. Final decisions about coding belonged to the lead researcher. These initial readings and discussions generated a provisional code list. 
The research questions were reviewed by the lead researcher to ensure that each research question was represented. Then, a third researcher read each transcript and completed grids for each research question (Miles \& Huberman, 1994). There were separate grids for each stakeholder group (i.e., representing judges, service providers, foster care providers, parents, and youths). These grids provided snapshots of each stakeholder group's reports (Miles \& Huberman, 1994).

After completing the grids, the third researcher coded each transcript so that the two sets of coded transcripts could be compared. When disagreement occurred, the researchers discussed it until reaching consensus. Again, the lead researcher made final coding decisions. Coding continued with codes being added and refined until the final coding guide was complete. The lead researcher then revisited transcripts coded with earlier guides and recoded them with the final coding guide. Throughout this process, there were eight versions of the coding guide. When final coding was complete, there were 24 code categories and 103 subcode categories. Ethnograph facilitated organization of data (The Ethnograph, 1998).

After all transcripts were coded, the lead researcher considered the volume of available information and determined that the inductive approach yielded many more code categories than were needed to answer the research questions. Next, the lead researcher reviewed the code categories and determined which codes answered the research questions. This approach was consistent with using the theoretical orientation to guide analysis and direct attention to certain data while filtering out extraneous data (Yin, 1994). The lead researcher then used The Ethnograph to sort information relevant to each research question. Transcript excerpts from each code category were then reviewed and analyzed (Miles \& Huberman, 1994; Taylor \& Bogdan, 1998). The lead researcher examined the information in two ways: (a) by family group (i.e., a youth, his/her parent(s), foster care provider, service provider, and judge; and (b) by stakeholder group (i.e., the youths, the parents, the foster care providers, the service providers, and the judges). Topics and code chunks under analysis were summarized. In some cases, categories were broken down into smaller categories for comprehension.

An audit trail and peer review supported credibility and dependability (the parallel to reliability in quantitative research) (Erlandson, Harris, Skipper, \& Allen, 1993; Schwandt and Halpern as cited in Huberman \& Miles, 1994). The researchers enhanced confirmability (which addresses the issue of whether others could examine the data and understand how the researcher reached the conclusions) by using a reflexive file, maintaining an audit trail, and completing a confirmability audit (Erlandson et al., 1993; Marshall \& Rossman, 1995). An outside expert researcher conducted the confirmability audit during the latter part of data analysis.

Triangulation of date enhanced credibility (the extent that others feel confident that participants and the area under study are presented accurately) (Denzin, 1994; Erlandson et al., 1993; Lincoln \& Guba, 1985). Triangulation occurred in three ways: (a) obtaining information through more than one method (in-depth interviews and document analysis); (b) collecting information from multiple sources (youth, foster care providers, families of origin, judges, and service providers; and (c) involving at least two researchers in the analysis (Erlandson et al., 1993). In addition, the lead researcher conducted member checking with participants throughout the interview process by confirming impressions 
and clarifying information gathered in previous interviews (Erlandson et al., 1993). Throughout the analysis process, the lead researcher occasionally presented tentative findings to the PAR committee and solicited their comments. After the final analysis, the PAR committee received a summary of findings, and members were asked to comment. Summaries of findings were mailed to all participants who could be located (70\%), which gave them an opportunity to respond. The lead researcher included paper, a self-addressed, stamped envelope, and a toll-free telephone number so participants could respond easily and at no personal expense. No responses from participants or from PAR committee members contradicted the findings.

\section{Findings}

The ASFA affected all study participants in some way, but not everyone knew about the ways that ASFA affected them. The judges all spoke about ASFA and its impact, while some biological parents, service providers, foster care providers, and one youth discussed the ASFA either directly or indirectly.

Participants did not see a direct impact on access to services, but did notice indirect effects. In short, participants believed that the ASFA shortened the amount of time families had to correct problems during the time the child was in custody. Some service providers may feel less inclined to help the family because the law seems to not require as much from service providers as in the past. Furthermore, when the court is at the point of making a decision about the family, it is more likely to opt for termination of parental rights than for reunification. The findings from this study are discussed according to these three themes.

\subsection{Shortened timeframe}

Participants spoke about the ASFA's affect on timelines and noted that families move through the system more quickly under the ASFA. The decision-making process is faster, which may indirectly decrease children and families' access to services. If families move through the system more quickly, they have less time to access services. Some saw these time factors as beneficial, while others had concerns about them. Those who believed the new pace was beneficial cited (a) the potential to prevent out-of-home placement or expedite reunification and (b) the potential to provide fewer services as part of "reasonable efforts" that would expedite termination of parental rights. Participants spoke of the potential for these things to happen, but not necessarily that they were happening under the ASFA. Those who believed that a swift move through the system was detrimental believed that the time limits are too short for families who might not be able to make quick changes, but whose members should not be separated.

Participants who were positive about a shortened time frame believed that families would address problems more quickly and move out of the system more quickly because of reunification or termination. Typical responses from judges included the view that a faster timeline is beneficial as long as the state does not remove children from their homes when the family could be preserved, given the right services. A service provider and a 
foster care provider endorsed the faster timeframe, citing young children's need for permanency and stability with comments such as, "If their parents can't get it together, they need to sever" and "I've just seen what difference the kids can make when they have the permanency... They are just like a new little individual because they don't have that extra stress hanging over their head."

Some participants assessed the ASFA's timelines as detrimental and said that the timelines do not give families adequate time to address family issues that have persisted for years. The same judge who saw benefit in helping children achieve permanency also noted a "conflict between the child's interest and the dysfunctional parent all of a sudden having to toe the line."

These folks are brought into court and told, "Look, you've got to get these items done." And it's three pages long or four pages long, and you got 4 months or 6 months to do it, and they've never been organized in their life. I'm convinced-I try and explain it in plain layman language-I'm convinced when they get out in the hallway, they don't know what I said. They don't know what they've got to do, so someone's got to take them by the hand, tell them that they've got to do this sophisticated job within 6 months because I've got to meet my one-year time frame. It's asking a lot.

A youth spoke of the difficulty this timeline posed for his brother, saying, What about these kids with really bad problems that they need, more, more, more, more time to work out? That's why I think they're screwing (my stepfather) over and they're kind of screwing my brother over. I don't really want to see him go to another family... In some families it's ok, but some other ones it ain't, because what if the child has problems and it's going to take more than a year to get fixed? And then they run out of time... It's like they're on a quickened time. They got to hurry up and do things quick instead of making it happen like, you know, slow. Things do happen slowly. That makes the parents more worried that they got a hearing. You know, they got to do this and that. So it ain't really going to help. And the parents, they know they got a year and they're trying all this and that. It's more frustrating.

A few participants had mixed feelings about the shortened timeframe with a judge explaining, "It's made us process cases faster. I suppose that's good. I'm not sure sometimes. Sometimes it forces us into a decision that I'm not sure is appropriate."

A foster care provider saw the timelines working against families by giving parents too much or too little time, depending on individual family circumstances.

In some cases, for somebody to say they have a year to get these kids home, is unrealistic. In other cases to say, "I'm giving you a year to get your stuff together" is unrealistic. I mean, it's unrealistic for the parents who you already know could care less. Why should we let these children become another year or two or three or four years older before they actually get moved on to the adoption agency... I feel sometimes they don't give the parent enough time. When the parents are trying, they don't give them enough time. It's the ones who aren't trying - they give them too much. 


\subsection{Push for termination of parental rights}

Some participants believed the ASFA pushes for termination of parental rights (TPR) rather than reunification. Some regarded an emphasis on TPR as commendable, but others disagreed. Those who saw TPR as a detriment asserted there is pressure to terminate even when this is not in the child's best interest. Those who regarded TPR as commendable believed it is good for young children, in particular, to move toward adoption when possible.

Some participants believed the court severs parental rights and moves children toward adoption when such decisions are not beneficial to the child. Further, some judges believed that the ASFA reduces their discretion and pushes them to terminate parental rights. The youth participants, especially, were opposed to TPR:

A judge explained the feeling of losing judicial discretion by saying,

Sometimes it forces us into a decision that I'm not sure is appropriate- "Now we've got to do this, or else" sort of thing. . I kind of resent being (told), "You've got to do this or that"... I know (the state government) is under mandate from the Federal government, but it frustrates me. These people sit up there. They enact this legislation and sometimes they don't see the real world. They don't see the practical effect of their legislation.

Each youth reported wanting to return to his or her family of origin, or at least wanting to try making reunification work. Even the youths who had several years of foster care experience did not want courts terminating their parents' rights and moving them to adoptive placement. One youth with no chance of reunification explained, "Well, I know that (contractor) had asked me if I wanted to be adopted or whatever and I was like, 'No.' I said, 'I don't think I need it.' " Another youth stated,

I wouldn't feel comfortable going to an adoptive family. Not being able to see my brothers. The other thing is my real dad is all a sudden coming in the picture. Another thing is my mother. I don't want to leave her. My mother has tried so hard on me.

A foster care provider explained that a child's long-term placement does not necessarily mean he is "languishing in the system." In the case of his foster child, he stated,

If they had forced (youth) in a year's time into doing something-You know, if they were to say, OK (youth), you've been in foster care a year now, we need to go do something else," I think it could have been adverse instead of what it was intended to do. It was intended for people not to be just stuck in the system, but in (his) case, if he would have been forced into something, I think it would not have been for his best interest. . I'm sure there's probably a lot of other kids out there just like him. But you know, that may not be languishing in the system. They may be happy where they're at, and it's a stable situation for them. More stable than if they were just forced to go into adoption or something.

By contrast, some participants favored TPR, even in the absence of an identified adoptive placement. A foster care provider believed earlier termination of parental rights and a move for adoption is positive for young children, saying, 
Kids need permanency. You get these little kids that bounce around; they need permanency when they're little. If their parents can't get it together, they need to sever. Instead of bouncing these kids around until they're teenagers. The world's full of teenagers that don't have parents now. They're much more adoptable when they're little.

\subsection{Reasonable efforts}

Some participants spoke about the "reasonable efforts" language that is in ASFA and this language's impact on families. Participants were divided in their beliefs about its impact. Some concluded that it would prevent unnecessary out-of-home placements, others believed it might decrease services to families, and still others believed that it does not affect services. One judge spoke about reasonable efforts, saying,

Really all the Adoption and Safe Families asks us to do is (ask), "Is it contrary to the welfare of the child to be in the home and have we used reasonable efforts to keep from removing the child?" I think that is the only way this system can work. Just every once in a while-you know we have-I don't know, I don't know if (youth) would have been taken out of the home since 1994 if we'd really made a good hard look at that back then.

Another judge spoke of the potential to decrease services provided to families. This judge believed that the ASFA's clarification of reasonable efforts would result in service providers requiring more of families and not "doing too much" for them. She stated that service providers should learn about the law so they would do less for and require more of the families.

A service provider stated that language defining reasonable efforts in ASFA has not affected services to families, but merely affects documentation that service providers carry out.

We have to have more detailed reports, and specifically, reasonable efforts have to be stated on all the journal entries. So they have to be recorded in the court minutes. So, we have to prove that we have tried to get this kid home. That we have tried to unite these children and all our reasonable efforts are not coming to the forefront... We've always tried to do that, but now we have to show best interest of the child. In words and in reports.

\section{Discussion}

Congress enacted the ASFA to help children move from foster care into safe, permanent homes in a timely manner. The ASFA includes time limits for making placement decisions, clarification of reasonable efforts for reunification, and financial incentives to states for increasing the number of adoptive placements each year. 
The study participants indicated that judges and service providers are working to follow the ASFA's time limits. However, not everyone agrees that these time limits are best for children and families. In addition, not all participants agree that TPR and adoption are the best alternatives for many children, especially older youths. There are cases in which finding consensus about placement is relatively easy. One participant explained:

If they ran hot water on them or they scratched out their eyes, baked them in the oven, we know... I'm not hopeful that we can change very much with the family who has done something so absolutely terrible to the children. And in that case 12 months is probably too long.

The ASFA tries to help people make prompt decisions in hard cases (Adler, 2001). With some exceptions, the decision is between reunification and TPR with presumption that adoptive placement will follow. There are two challenges involved in making this decision. First, the family has a limited time to access services. If service access is a problem, this tips the scale toward TPR. Second, when decision-makers are faced with termination versus reunification, TPR may seem like the less risky choice, again tipping the scale toward TPR (Adler, 2001).

\subsection{Shortened timeframe}

One problem with the goal of timely permanency is the risk of severing a youth's ties in order to move him or her into permanent placement. When a child's early attachments are disrupted, the chances for negative developments increase. When state policies create disruption, the state is putting children at risk (Willemsen \& Marcel, 1996). When termination of parent rights is accelerated, another unintended consequence can be separation of siblings. Children may not achieve adoptive placement quickly when they are part of a sibling group (Patton \& Latz, 1994).

Although ASFA may successfully free children for adoption, large numbers often remain in foster care. In 2002, there were 129,000 children in foster care waiting to be adopted. That year, 53,000 children were adopted nationwide (Macomber, Scarcella, Zielewski, \& Geen, 2004). In a state-by-state analysis of barriers and promising approaches to finding adoptive placements for children in foster care, 47 states reported barriers to finding enough adoptive homes. The two barriers mentioned the most were (a) finding homes for children with special needs such as older children, sibling groups, or children with behavior problems or disabilities; and (b) finding homes that reflect the racial or ethnic diversity of the children (Macomber et al., 2004).

Ensuring that families have access to services is crucial, and may prevent out-of-home placements related to issues such as poverty, a youth's behavior, or parental substance abuse. Timely access to services while a child is in out-of-home placement is also very important. With the ASFA's timelines, families' needs must be addressed as soon as possible. Services that families typically access should be evaluated for effectiveness so service providers and judges can recommend services with confidence and families can be sure of the benefits. 


\subsection{Tipping scale toward TPR}

Some study participants expressed concerns about the AFSA's apparent push for TPR and adoption. Participants also said they need more placement options, not merely availability of a range of placements, but also a need for recognition that residential or hospital settings are the most appropriate placements for some youth. In addition, two judges complained that the ASFA reduces their judicial discretion. These concerns can be addressed by (a) clarifying the amount of individualization the ASFA allows, and (b) broadening the view of acceptable placements.

If judges and child welfare workers understand that the ASFA still allows for options other than TPR or reunification, they should feel free to abandon the TPR vs. reunification dichotomy. No change in the ASFA or in Kansas law is required to make this happen.

Once a child is in an out-of-home placement, the state works on reunifying the family or terminating parental rights. Whether a family is reunified or parental rights are terminated, the decision is meant to benefit children by giving them permanent placement. However, the notion of "permanent" placement can be misleading. It may be easier to let go of the push for TPR and adoptive placement when one realizes that a permanent placement is not always truly permanent. A permanency plan has the potential to disrupt as long as (a) the child's future safety is uncertain, (b) there is a shortage of adoptive homes, and (c) children long for their families (Adler, 2001). In addition, older children are less likely to be adopted than are younger children, and children with disabilities experience a high rate of disrupted adoptions (Schwartz \& Fishman, 1999). For these children, TPR with a goal for adoption may not be the best option.

The ASFA focuses on a TPR-versus-reunification dichotomy. However, the ASFA does provide some exceptions. It is unrealistic to believe that TPR or reunification are the only appropriate choices for all children in foster care. The question of termination versus reunification may be avoided by remaining open to other solutions and considering TPR or reunification as just two of many solutions (Adler, 2001). Eliminating other options does not eliminate the need for other options.

Adler (2001) describes two situations in which a team of diagnosticians moved juvenile offenders out of the prison environment by using a range of options. In these cases, when the options included either incarceration or parole, decision-makers opted for incarceration for $95 \%$ of the youth, because it was the safer choice for the community. However, when decision-makers were free to choose from a variety of options (e.g., wilderness programs, halfway houses, foster care, special monitoring, fulltime attendants, day treatment, vocation programs), decision-makers opted for incarceration for only $10 \%$ of the youth. Further, when the guidelines forced decision-makers to make decisions between the two options of parole or incarceration, the youth had a higher rate of recidivism than when the decision-makers had many options from which to choose.

As previously stated, the ASFA does not require states to file to terminate parental rights if (a) a relative is caring for the child or (b) the state has documented a compelling 
reason that filing a petition would not be in the best interest of the child (42 U.S.C. 675(5), 2000). For example, Kansas allows for the following:

If the secretary has documented to the court a compelling reason why custody for adoption, custody for permanent guardianship, nor custody for placement with a fit and willing relative are currently a viable option, the court may order custody to remain with the secretary for continued permanency planning and another planned permanent living arrangement (Kansas Code for Care of Children, 1999).

None of the states defined "compelling reasons" when passing state legislation to comply with the ASFA (Christian, 1999). If a court and the state agency have what they consider "compelling reasons," they may elect to consider options outside of the TPRversus-reunification dichotomy.

Emotional disability may be a compelling reason not to terminate parental rights. Children who are in out-of-home placement for reasons related to their emotional or behavioral challenges need treatment rather than termination of family ties. Because ASFA allows states to avoid seeking TPR when it is not in the child's best interest, no change to federal or state law is required. Some advocate, however, making this explicit. The Federation of Families for Children's Mental Health (FFCMH) advocates an amendment to ASFA stating that when determining whether there is a compelling reason not to seek TPR, the state must consider whether the child went into out-of-home placement primarily for treatment of a physical or mental condition. If the state determines that this was the case, the FFCMH's position is that the state must make plans to return the child to his or her parents' physical custody, if appropriate. In addition, it must provide necessary mental health services to the child, his or her family, and if appropriate, the family with whom the child is currently residing (Federation of Families for Children's Mental Health, 2002).

The previous section focused on the placement goal and the need for more options in addition to reunification or TPR. Placement-type goes hand-in-hand with the placement goal. When decision-makers are free to move away from the TPR-versus-reunification dichotomy, they are also free to examine a wide range of options, as in Adler's (2001) example of placements for juvenile offenders described above. The courts and child welfare workers should not sacrifice an appropriate placement in order to find a permanent placement. Children and youth should be in appropriate placements suited to each child's individual needs. This broad range of placements could include placements such as shared family care (i.e., the family stays with a host family) (Barth, Price, \& Simmel, 2000; Baxter, Cummins, Volard, \& da Costa, 1992), continued foster care or kinship care, placement in the home with full-time attendants, part-time placement in the home and part-time foster care placement, day treatment, or vocation programs. This list is by no means all-inclusive. If given the freedom to do so, the youth, their families, and the professionals working with them could come up with any number of options that could be individualized for each family.

\subsection{Differences in perspectives}

Obtaining family perspectives on the ASFA was different from obtaining perspectives of judges and service providers. Parents did not present issues in terms such as "This 
happened because of ASFA," "This happened because of privatization," or "This happened because of a specific agency's policies." Their views were understandably more global. Family perspectives differed from perspectives of service providers and judges in their knowledge base and areas of concern. Judges and service providers deal with the ASFA every day. In contrast, families deal with family members and service providers every day. Families, therefore, were more likely to focus on relationships with their children, relationships with service providers, and things that were "getting in the way" for them. Judges and service providers were more likely to focus on laws and policies (although relationships came up there, too) and why difficulties arise out of these laws and policies.

\subsection{Limitations}

This research focused on youths with emotional or behavioral challenges who were in out-of-home placements. One of the study's strengths was its in-depth information from a range of stakeholders. However, within subsections there were not enough respondents from each group of stakeholders to sort out differences by location of the state or by stakeholder type.

A potential limitation of the study was its retrospective nature. It is likely that participants' immediate foster care experiences overshadow their past experiences. In addition, over the course of the study, the privatized system was continually changing. Interviews took place over a period of 8 months. During that time, the first round of contracts ended and new contracts began. Further, for some participants, it may have been difficult to discern whether an issue was attributable to the ASFA or to privatization.

Finally, conclusions might be different if the sample were drawn from a different subset of the foster care population (e.g., cases for which abuse or neglect was the main issue leading to out-of-home placement). However, the reader may find relevance to other contexts.

\subsection{Final thoughts}

The authors do not advocate turning back the clock and allowing children and youth to languish in out-of-home placements. They do advocate planned, purposeful decisions that are based on the child's best interests and are individualized. There are no easy answers or simple solutions to challenges that families such as the participant families face. Nevertheless, there is much to be learned from them and from the foster care providers, service providers, and judges who are involved with families. By listening to families and other stakeholders, policy makers, educators, and other change-agents may find solutions that enhance the families' lives and stakeholders' work.

\section{References}

Adler, L. S. (2001). The meanings of permanence: A critical analysis of the Adoption and Safe Families Act of 1997. Harvard Journal on Legislation, 38(1), 1-36. 
Administration for Children and Families. (2003). National adoption and foster care statistics. Washington, DC: U.S. Department of Health and Human Services.

Banyard, V., \& Miller, K. E. (1998). The powerful potential of qualitative research for community psychology. American Journal of Community Psychology, 26(4), 485-504.

Barth, R. P., Price, A., \& Simmel, C. (2000). Caring for the whole family to keep the family whole. Children's Voice, 9(1), 24-27.

Baxter, C., Cummins, R. A., Volard, J., \& da Costa, C. (1992). Shared family care: Policy implementation during the initial stage of service development. Australian Disability Review, 2, 63-72.

Berg, B. L. (1998). Qualitative research methods for the social sciences (3rd ed.). Boston: Allyn \& Bacon.

Breda, K. L., Anderson, M. A., Hansen, L., Hayes, D., Pillion, C., \& Lyon, P. (1997). Enhanced nursing autonomy through participatory action research. Nursing Outlook, 45(2), 76-81.

Children's Defense Fund. (2004, July 16). Children in Kansas, from http://www.childrensdefense.org/data/ childreninthestates/ks.pdf

Christian, S. (1999). 1998 State Legislative Responses to the Adoption and Safe Families Act of 1997. State Legislative Report, 24(5) (Online: www.ncsl.org/programs/cyf/asfaslr.htm).

Denzin, N. K. (1994). The art and politics of interpretation. In N. K. Denzin, \& Y. S. Lincoln (Eds.), Handbook of qualitative research (pp. 500-515). Thousand Oaks: SAGE Publications, Inc.

Docherty, S., \& Sandelowski, M. (1999). Focus on qualitative methods: Interviewing children. Research in Nursing \& Health, 22(2), 177-185.

Erlandson, D. A., Harris, E. L., Skipper, B. L., \& Allen, S. D. (1993). Doing naturalistic inquiry: A guide to methods. Newbury Park: SAGE Publications, Inc.

Federation of Families for Children's Mental Health. (2002). Relingquishing custody to obtain necessary treatment. Alexandria, VA: Federation of Families for Children's Mental Health.

Gatenby, B., \& Humphries, M. (1996). Feminist commitments in organisational communication: Participatory action research as feminist praxis. Australian Journal of Communication, 23(2), 73-87.

Honey, M. A. (1987). The interview as text: Hermeneutics considered as a model for analysing the clinically informed research interview. Human Development, 30, 69-82.

H.R. Rept. No. 105-77, 105th Cong. 2d Sess., (1997).

Huberman, A. M., \& Miles, M. B. (1994). Data management and analysis methods. In N. K. Denzin, \& Y. S. Lincoln (Eds.), Handbook of qualitative research (pp. 428-444). Thousand Oaks: SAGE Publications.

Humphrey, K. R. (2002). The impact of service access on out-of-home placement for youth with emotional disabilities and their families (Doctoral dissertation, University of Kansas, 2002). Dissertation Abstracts International, 63(10A), 3728.

Humphrey, K. R., Turnbull, A. P., \& Turnbull, H. R. (in press). Perspectives of foster care providers, service providers, and judges regarding privatized foster care services. Journal of Disability Policy Studies.

Kadushin, A. (1990). The social work interview. New York: Columbia University Press.

Kansas Code for Care of Children. (1999). (Legal No. K.S.A. 1998 SUPP. 38-134; 38-1501 thru 38-1598) (1999). Kansas Dept. of Social and Rehabilitation Services Legal Division, Children and Family Services Commission.

Lincoln, Y. S., \& Guba, E. G. (1985). Naturalistic inquiry. Newbury Park: SAGE Publications, Inc.

Macomber, J. E., Scarcella, C. A., Zielewski, E. H., \& Geen, R. (2004). Foster care adoption in the United States: A state-by-state analysis of barriers and promising approaches. Washington, DC: Urban Institute.

Marshall, C., \& Rossman, G. B. (1995). Designing qualitative research (2nd ed.). Newbury Park: SAGE Publications, Inc.

Miles, M. B., \& Huberman, A. M. (1994). Qualitative data analysis: An expanded sourcebook (2nd ed.). Thousand Oaks: SAGE Publications, Inc.

Morse, J. M. (1994). Designing funded qualitative research. In N. K. Denzin, \& Y. S. Lincoln (Eds.), Handbook of qualitative research (pp. 220-235). Thousand Oaks: SAGE Publications, Inc.

Patton, M. Q. (1990). Qualitative evaluation and research methods (2nd ed.). Newbury Park: SAGE Publications, Inc.

Patton, W. W., \& Latz, S. (1994). Severing Hansel from Gretel: An analysis of siblings' association rights. University of Miami Law Review, 48, 745. 
Penuel, W. R., \& Freeman, T. (1997). Participatory action research in youth programming: A theory in use. Child and Youth Care Forum, 26(3), 175-185.

Reason, P. (1998). Three approaches to participative inquiry. In N. K. Denzin, \& Y. S. Lincoln (Eds.), Strategies of qualitative inquiry (pp. 261-291). Thousand Oaks: SAGE Publications, Inc.

Schwartz, I. M., \& Fishman, G. (1999). Kids raised by the government. Westport: Greenwood Publishing Group Incorporated.

Stake, R. E. (1998). Case studies. In N. K. Denzin, \& Y. S. Lincoln (Eds.), Strategies of Qualitative Inquiry (pp. 86-109). Thousand Oaks: SAGE Publications, Inc.

Taylor, S. J., \& Bogdan, R. (1998). Introduction to qualitative research methods: A guidebook and resource. New York: John Wiley \& Sons, Inc.

The Ethnograph (Version 5.0) (1998). [Computer software]. Amherst, MA: Qualis Research Associates.

Turnbull, A. P., Friesen, B. J., \& Ramirez, C. (1998). Participatory action research as a model for conducting family research. $J A S H, 23(3), 178-188$.

Willemsen, E., \& Marcel, K. (1996). Attachment 101 for attorneys: Implications for infant placement decisions. Santa Clara Law Review, 36, 439.

Woodhouse, L. D., \& Livingood, W. C. (1991). Exploring the versatility of qualitative design for evaluating community substance abuse prevention projects. Qualitative Health Research, 1(4), 434-445.

Yin, R. K. (1994). Case study research: Design and methods (2nd ed. Vol. 5). Newbury Park: SAGE. 